\title{
Regulamento para Inspeção Médico-Escolar no Rio Grande do Norte (1923)
}

No governo de Antonio José de Mello e Souza e de Augusto Leopoldo Raposo da Camara no Rio Grande do Norte (1920-1923), a expansão da educação escolar primária, bem como o desenvolvimento da educação sanitária de alunos e professores mereceram a atenção das autoridades educacionais e médicas do Estado. No ano de 1923, o Diretor da Instrução Pública junto aos médicos da Diretoria-Geral de Higiene, com base nos preceitos teóricos e conhecimentos da pedagogia nova e da pedagogia científica, criaram o Serviço de Inspeção médico-Escolar orientado pelo Regulamento para Inspeção Médico-Escolar no Rio Grande do Norte (1923), visando ao cumprimento do artigo 204 da Lei n 405, de 29 de novembro de 1916. Considerando a relevância desse Regulamento de 1923 para a História da Educação do Rio Grande do Norte e do Brasil, é que se publica nesta Seção de Documento.

Marta Maria de Araújo Editora Responsável da Revista Educação em Questão

\section{Capítulo I}

\section{Da organização e fins do serviço}

Art. $1^{\circ} \mathrm{A}$ inspeção médico-escolar, criada pelo Decreto $\mathrm{n}^{\circ} 209$ de 8 de maio, para cumprimento do art. 204 da Lei n 405, de 29 de novembro de 1916, constituirá uma seção da Diretoria Geral de Higiene e Assistência Pública.

Art. $2^{\circ} \mathrm{A}$ inspeção abrangerá todos os estabelecimentos estaduais, municipais e particulares de ensino primário, normal, profissional e secundário de todo o Estado.

Art. $3^{\circ} \mathrm{A}$ inspeção médico - escolar além do disposto pelo art. $3^{\circ}$ do Decreto de 8 de maio de 1923, visará ainda:

I A educação sanitária dos alunos e dos professores;

Il A sistematização dos exercícios físicos;

III A profilaxia das moléstias transmissíveis ou evitáveis. 
Art. $4^{\circ} \mathrm{A}$ inspeção médico - escolar, auxiliada pelo pessoal docente dos estabelecimentos de educação, será praticada:

a) Na capital, pelos médicos da Diretoria Geral de Higiene e pelos que para tal fim forem comissionados pelo governo;

b) Nos municípios em que houver delegado de Higiene, por este, e nos outros por profissionais contratados.

Art. $5^{\circ}$ A vigilância das escolas e locais anexos, do mobiliário e material escolar, far-se-á por meio de visitas periódicas com indagações sobre tudo quanto possa interessar à saúde do escolar.

Art. $6^{\circ}$ Nas visitas, que a autoridade competente fizer as escolas, terá em consideração especial:

I Com relação ao local:

a) que o asseio do prédio, onde funciona a escola, seja completo em todas as dependências;

b) que a iluminação e ventilação das salas de aulas sejam convenientes, de acordo com os preceitos higiênicos relativos à espécie;

c) que a cubação seja adequada e proporcional ao número de alunos;

d) que haja adaptação conveniente dos lugares destinados aos jogos e exercícios dos educandos;

e) que a água potável seja submetida a um tratamento prévio de depuração;

f) que sejam observadas as exigências de limpeza e bom funcionamento dos lavatórios e aparelhos sanitários.

Il Com relação ao mobiliário e material:

a) que sejam construídos de acordo com o que preceitua a higiene escolar;

b) que o mobiliário seja adequado ao tamanho do escolar.

Art. $7^{\circ}$ Nos internatos deve a autoridade sanitária examinar cuidadosamente os alimentos, tanto no ponto de vista de sua qualidade e quantidade, como no modo de preparação.

$\S$ Único - As salas de dormitório serão inspecionadas no intuito de se verificar se tem boas condições de asseio, de ventilação e cubação indispensável ao número de alunos que alojem.

Art. $8^{\circ}$ Nenhuma autorização para a construção ou adaptação de prédios destinados a escola será dada sem prévia audiência da inspeção médico-escolar. 


\section{Capítulo II}

\section{Da inspeção dos alunos}

Art. $9^{\circ} \bigcirc$ exame individual dos alunos será praticado minuciosamente, na primeira vez em que forem submetidos à inspeção, em presença dos pais, se possível, e do professor a cuja classe pertença o escolar, sendo os exames seguintes apenas para verificação do seu estado.

I A ficha sanitária será constituída por uma caderneta, na qual serão inscritos, além de um número de ordem, nome, idade, filiação, naturalidade, residência, referência de vacinação e revacinação, os dados resultantes do exame fisiopatológico e físico.

II A ficha individual constituirá o histórico sanitário do aluno e servirá para julgar o desenvolvimento físico-psíquico do mesmo.

III Da ficha sanitária constarão as notações seguintes:

a) Aspecto geral;

b) Traços antropométricos;

c) Pele, couro cabeludo e sistema piloso;

d) Defeitos de conformação;

e) Estado dos órgãos torácicos, com pesquisas dos gânglios peribronquicos;

f) verificação da cavidade bucal, garganta e aparelho da fonação;

g) Estado dos órgãos abdominais;

h) Investigação dos órgãos dos sentidos, especialmente dos aparelhos visual e auditivo;

i) Dados psíquicos e psicopedagógicos.

Art. $10^{\circ}$ Os quesitos gerais da ficha e as observações psicopedagógicas deverão ser preenchidos pelo professor ou diretor do estabelecimento de ensino, reservando-se à autoridade sanitária os de ordem técnica.

$\S$ Único - As anotações da ficha sanitária deverão ser revistas em cada inspeção.

Art. $11^{\circ}$ Terminado o exame, o médico inspetor classificará o escolar.

Art. $12^{\circ}$ As fichas sanitárias ficarão arquivadas na escola ou instituto onde o aluno estiver matriculado, acompanhando-o sempre que for transferido para outra escola. 
Art. $13^{\circ}$ Os dados da ficha sanitária poderão ser fornecidos aos pais, tutores ou protetores dos alunos, quando por eles reclamados.

Art. $14^{\circ}$ Terminado o período escolar, o médico inspetor, quando consultado, poderá, pela ficha escolar, aconselhar sobre a profissão ou ofício que deve seguir o aluno, tendo em conta a sua saúde geral e o estado dos seus diferentes órgãos.

Art. $15^{\circ}$ Os professores, docentes e empregados são sujeitos às mesmas inspeções.

$\S 1^{\circ}$ - Em caso de tuberculose aberta, sífilis com acidentes contagiosos, ou lepra, os doentes serão excluídos, ou afastados das escolas até a cura.

$\S 2^{\circ}$ - Todo candidato ao magistério será submetido à inspeção.

\section{Capítulo III}

\section{Da educação sanitária}

Art. $16^{\circ} \mathrm{A}$ educação sanitária dos alunos e professores consistirá na divulgação de preceitos e conhecimentos de higiene escolar:

284 I Para o professor:

a) conhecimento de preceito relativos à higiene das habitações e especialmente das escolas;

b) da atitude normal e simétrica do escolar em pé e assentado;

c) dos meios de evitar a fadiga mental de escolar, fixando a duração do trabatho, do repouso e do sono, e a qualidade e quantidade de alimentação;

d) a correção dos maus hábitos dos escolares, adquiridos na rua ou em casa, mediante conselhos e instruções aos pais e aos próprios alunos;

e) a colocação apropriada nas classes, dos alunos que tenham alterações visuais ou auditivas;

f) meios práticos tendentes a pôr o pessoal, que frequenta a escola ao abrigo das moléstias evitáveis;

g) o conhecimento dos prodromos e sintomas da invasão das moléstias infectocontagiosas.

II Para os alunos deve se ter em vista:

a) o amor ao asseio e conhecimento das vantagens que dele decorrem; 
b) o combate aos vícios e indicação dos seus inconvenientes;

c) o horror ao álcool e o perigo a que se expõem os intemperantes;

d) a vantagem dos hábitos regulares quanto à alimentação, ao sono, aos exercícios, aos banhos, etc.

Art. $17^{\circ} \mathrm{A}$ inspeção médico-escolar aconselhará a educação física efetiva e de acordo com os princípios científicos, no sentido de proporcionar o desenvolvimento metódico e harmônico do escolar, favorecendo-lhe as aptidões físicas e recomendando:

a) o emprego judicioso dos exercícios físicos;

b) a descriminação dos escolares que podem seguir o curso normal no todo ou em parte, e dos que carecem de cuidados especiais;

c) a classificação dos alunos, segundo o seu desenvolvimento físico.

\section{Capítulo IV \\ Da profilaxia escolar}

Art. $18^{\circ}$ A prevenção das moléstias transmissíveis e evitáveis consiste na verificação médica dos estados suspeitos e conseqüentes providências, de acordo com as leis e regulamentos em vigor.

Art. 19 Sempre que o aluno não compareça à escola, por doença ou sem causa justificada, será exigido um atestado para certificar-se da causa verdadeira do não comparecimento.

$\S 1^{\circ}$ - Verificado que se trata de uma moléstia transmissível, serão tomadas medidas adequadas no intuito de impedir a disseminação, e assegurar a saúde da coletividade.

$\S 2^{\circ}$ - Tratando-se de moléstia de notificação compulsória, será feita a devida comunicação à autoridade competente.

Art. 20 Verificada a existência de moléstia transmissível no domicílio de um aluno, não poderá este voltar a escola sem que seja debelada a moléstia, e apresentando um documento comprobatório do completo expurgo do domicílio.

$\S 1^{\circ}$ - Verificado que se trata de uma moléstia transmissível, serão tomadas medidas adequadas no intuito de impedir a disseminação e assegurar à saúde da coletividade. 
$\S 2^{\circ}-\bigcirc$ atestado para readmissão, será fornecido gratuitamente pelo médico-inspetor.

Art. $21^{\circ} \mathrm{Em}$ caso de aparecimento de epidemia, a autoridade sanitária poderá propor o fechamento da escola por tempo determinado.

Art. $22^{\circ}$ As moléstias contagiosas, que justificam o afastamento dos alunos, são:

I Sarampo, escarlatina, varicela, erisipela, gripe, cólera, varíola, difteria, tifo, disenteria, tuberculose, coqueluche, parotidite, sífilis e meningite cérebro-espinhal.

II As oftalmias infectuosas, sarnas, tinhas, pediculoses;

III As moléstias nervosas, contagiosas por imitação, os tics, a histeria, a epilepsia.

Art. $23^{\circ}$ Os professores e empregados ficam sujeitos ao afastamento pelos mesmos motivos.

\section{Capítulo V}

\section{Da direção do serviço médico}

Art. $24^{\circ}$ Enquanto o Estado não puder dar maior desenvolvimento ao serviço, a direção deste caberá à Diretoria Geral de Higiene, à qual compete:

I Organizar a inspeção médica das escolas do Estado, distribuindo o serviço e fiscalizando a sua execução;

II Atender às consultas e requisições, orais ou escritas, dos médicos-inspetores e dos interessados;

III Convocar os inspetores para uma ou duas reuniões anuais, tomar conhecimento dos trabalhos, mandar registrar os dados estatísticos, que lhe forem presentes, corrigir e orientar a ação dos seus auxiliares;

IV Designar os médicos inspetores, que em caso extraordinário, tiverem de seguir para o interior do Estado, a serviço da inspeção médico-escolar;

$\checkmark$ Apresentar ao governador, até 5 de outubro de cada ano, o relatório dos serviços executados durante o ano, fazendo-o acompanhar de informes estatísticos.

Art. $25^{\circ} \mathrm{Na}$ falta ou impedimento do Diretor da Higiene, desempenhará estas funções o médico-inspetor designado pelo governo. 


\section{Capítulo VI}

\section{Dos médicos inspetores}

Art. $26^{\circ}$ Compete a cada um dos médicos-inspetores:

I Em relação aos estabelecimentos de ensino a seu cargo:

a) examinar cuidadosamente os alunos das várias classes de ensino, coligindo todos os dados necessários a vista do exame geral e especial de cada um, de modo a constituir as respectivas fichas; e, em razão delas classificá-los entre os alunos normais e anormais, especificando neste caso em que consistem as deficiências observadas e qual o regime especial que reclamam;

b) examinar os empregados administrativos, professores e auxiliares do ensino, assim como os candidatos ao exercício dessas funções, comunicando ao diretor o resultado da sua observação, e propor-lhe quando possa interessar à higiene individual e coletiva;

c) visitar periodicamente as escolas e dependências orientando os docentes e reclamando do diretor o que the parecer conveniente ao melhor funcionamento escolar, sob o aspecto médico-sanitário;

d) vacinar e revacinar os alunos e demais pessoas, que com eles convivem;

e) solicitar dos diretores e professores todo o auxílio, que precisem, para a execução do serviço a seu cargo;

f) fornecer atestados para readmissão dos escolares, temporariamente afastados da escola por moléstia;

g) praticar visitas suplementares na escola da sua jurisdição, todas as vezes que for necessária a sua presença.

II Em relação à repartição e aos estabelecimentos de que trata este Regulamento: a) comparecer às reuniões periódicas do corpo médico-escolar na capital, tomando parte na discussão dos assuntos referentes ao serviço e sugerindo os alvitres e providências que parecerem mais acertadas;

b) dizer sobre a planta dos edifícios escolares projetados em construção, assim como sobre os já ocupados e os que houverem de sê-lo por institutos de ensino; c) fornecer à repartição todas as informações concernentes ao seu raio de ação, bem como trimensalmente, os dados estatísticos correspondentes;

d) apresentar ao diretor, até 30 de setembro, um relatório sintético dos trabaIhos do ano; 
e) desenvolver em conferências públicas, mediante especial incumbência do médico-chefe, temas de higiene escolar;

f) atender escrupulosamente às recomendações, verbais ou escritas, do diretor, em tudo quanto entenda com a inspeção médico-escolar.

\section{Capítulo VII}

\section{Disposições gerais}

Art. $27^{\circ}$ Nos estabelecimentos de ensino, que tiverem médico próprio, o serviço da inspeção escolar poderá ser executado por este, contanto que o faça de acordo com as normas do Decreto de 8 de maio de 1923 e deste Regulamento, e forneça à direção do mesmo serviço às informações regulamentares.

Art. $28^{\circ} \bigcirc$ Governo fornecerá aos inspetores os aparelhos indispensáveis para os exames médico-escolares.

Art. $29^{\circ}$ Os casos omissos serão resolvidos pelo Governador, ouvidos o diretor de higiene e os inspetores.

Art. $30^{\circ}$ Revogam-se as disposições em contrário.

Palácio do Governo do Estado do Rio Grande do Norte, em Natal, 16 de maio de 1923, 35 da República.

Antonio José de Mello e Souza

Augusto Leopoldo Raposo da Camara

RIO GRANDE DO NORTE. Regulamento para Inspeção médico-escolar no Rio Grande do Norte. Actos Legislativos e Decretos do Governo (1923). Natal: Typographia d'A República, 1924. 